\title{
Federally-Mandated Evaluation of New Starts Transit Projects
}

\author{
David Laverny-Rafter \\ Minnesota State University, Mankato
}

\begin{abstract}
Over the last 20 years, numerous metropolitan regions in the U.S. have implemented new, and upgraded existing, rail and bus rapid transit (BRT) fixed guideway systems funded by the federal "New Starts" program. Now, one condition of receipt of federal New Starts funds is that the project sponsor conduct an evaluation, called a Before and After Study, to determine the cost and ridership impacts of the transit project. Upon completion of this study, it must be submitted to the Federal Transit Administration (FTA) of the U.S. Department of Transportation, which is mandated to summarize these reports and submit them as an annual New Starts Before and After Studies Report to Congress. Based on a review of the annual New Starts reports that have been conducted to date, this paper describes the key findings of these Before and After Studies and analyzes their implications for mandated program evaluation research in the transit field.
\end{abstract}

\section{Background}

Over the past 20 years, there has been a tremendous growth in interest by U.S. metropolitan regions in building new or expanding existing public transit systems. While most of the attention by local planners and policymakers has been on light rail projects, other fixed guideway systems have been built or expanded, including heavy rail subways and BRT busways. The federal program that partially funds fixed guideway transit projects is called New Starts and, as of 2003, 25 projects 
had received New Starts Full Funding Grant Agreements (FFGA) from FTA. Furthermore, 52 other transit providers were in some stage of New Starts planning and development and 151 potential New Starts projects were identified in the 2003 National Transportation Act (Dittmar 2004). Transit fared very well under the current national transportation law (called SAFETEA-LU) by authorizing $\$ 45$ billion in guaranteed funding over six years (an increase of 16\%). The reasons for this "boom" in transit investments are multiple, but "critics have charged that America's new rail projects have nothing to do with economics and everything to do with politics: city boosterism; and political monument building" (Cervero 1998, p. 440).

In an effort to balance the political influences in transit decision making with a data-driven, long-term investment perspective, federal officials and policymakers have called for expanding evaluation efforts associated with News Starts projects (Fisher 2003). In response to this demand for greater effectiveness and transparency, in 2001 the U.S. Congress mandated that Before and After Studies be conducted for all New Starts projects and that FTA report annually to Congress on the major findings of these studies. This paper describes the characteristics of the Before and After Study mandate, the findings of the Before and After Studies that have been implemented to date, and analyzes the implications for evaluation research in the transit field.

\section{The Evolution of Federal Evaluation Mandates}

Beginning in the 1960s, program evaluation has grown as a professional field and has been institutionalized through the use of federal evaluation mandates. Programs such as the War on Poverty, Medicare, Medicaid, and the Elementary and Secondary Education Act incorporated some form of systematic program evaluation and led to a tenfold increase in federal funding for evaluation by the 1970s (Carman 2008). Originally, these mandates focused on evaluating the effectiveness of individual programs in achieving their goals, but by the late 1960s, they were broadened to include performance-based management and budgeting. For example, the Planning, Programming and Budgeting Systems (PPBS) of the Johnson Administration, the Management by Objectives (MBO) approach of the Nixon Administration, and Zero Based Budgeting (ZBB) of the Carter Administration represented efforts to link budgetary decision making and public policies on program outcomes, as demonstrated in evaluation studies (Carman 2008). 
More recently, the Government Performance and Results Act (GPRA) of 1993 was an initiative whereby the federal government required federal agencies to improve the effectiveness of their programs and their accountability to the public by focusing on results, service quality, and customer satisfaction. Basically, GPRA requires that "federal agencies improve program management and Congressional decision-making by assembling objective information about program results and achievement of statutory objectives" (Federal Transit Administration 2003).

GPRA was unique in the evolution of evaluation legislation because it was administered by the U.S. Office of Management and Budget instead of the line Executive agencies and thereby directly linked budgeting decisions in the White House to program performance results. Another way that GPRA tried to achieve organizational reform was reflected in the requirement that federal agencies produce a strategic plan that included a performance element that would measure how each federal program was meeting its objectives (Carman 2008).

While GPRA illustrates the growing support for mandated program evaluation, there has been a lack of agreement as to methodology for implementing it. As a result, evaluation mandates generally have avoided stipulating a specific mode of data collection and standardization in the design of evaluation research (Manski 1990).

\section{FTA's Before and After Study Mandate}

As a response to GPRA, FTA believes that the Before and After Study will assist the agency in meeting the intent of GPRA and to carry out its responsibilities to document the accomplishments of the New Starts program (Federal Transit Administration 2003).

Therefore, in keeping with the spirit of GEPRA, in 2001 FTA issued its Final Rule on Major Capital Investment Project, mandating that New Starts projects conduct a Before and After Study. Specifically, the federal rule requires project sponsors who obtained a Full Funding Grant Agreement from FTA for New Starts projects submit a complete plan describing how they will collect and analyze Before and After information on the impacts of their projects and the accuracy of their forecasts.

To further strengthen the Before and After Study requirement, Title III of the 2005 national transportation act (SAFETEA-LU) codified the mandate that all New Starts sponsors prepare Before and After Studies. As was required in the Final Rule mentioned above, the SAFETEA-LU legislation mandates that all New Start 
applicants produce a plan that will describe the information to be collected and analyzed. The contents of this plan are to provide for:

1. The collection of data on the current transit system regarding transit service levels and ridership patterns, including origins and destinations, access modes, trip purposes and rider characteristics.

2. Documentation of the predicted scope, service levels, capital costs, operating costs, and ridership of the project.

3. Collection of data on the transit system two years after the opening of the new fixed guideway capital project, including analogous information on transit service levels and ridership patterns and information on the as-built, scope, and capital costs of the project.

4. Analysis of the consistency of predicted project characteristics with the "after" data. (Federal Transit Administration 2008)

Therefore, implementing before and after data collection procedures will permit project sponsors to produce an evaluation report that will serve internal and external constituencies by providing insights into the costs and impacts of major transit investments and improving the technical methods and procedures used in planning, forecasting, design, and construction of transit projects (Fisher 2003).

Ultimately, the intent of Congress in mandating this evaluation mandate was to produce Before and After Studies that achieve the following benefits:

1. Strengthen the New Starts program by highlighting the success of individual transit capital investments and the important role that transit plays in improving mobility and quality of life in communities throughout the nation.

2. Identify and transfer lessons learned in planning, implementing, and operating transit fixed guideway investments to agencies planning similar projects. Information generated from the Before and After Studies will enable the sponsors of future New Starts projects to build upon recipients' experiences with past projects including design and operational features that have proven successful, while avoiding options that have been less successful.

3. Identify the strengths and weaknesses in local procedures for predicting transit ridership and estimating capital and operating and maintenance costs, and identify ways that technical methods can be improved to support decision-making for future projects. 
4. Imbed within the planning and project development process the data assembly and analysis tasks that are needed to measure predicted and actualized project costs and impacts.

5. Accumulate a source of technical information on the actual costs and performance of major transit investments. (Federal Transit Administration 2008)

\section{Findings of Three Before and After Case Study Examples}

The 2003 SAFETEA-LU legislation required that FTA produce an annual Report to Congress that summarizes the results of New Starts Before and After Studies that have been submitted to FTA by transit sponsors. In meeting this Congressional evaluation mandate, FTA has had an "on-again, off-again" experience in obtaining Before and After Studies Reports from project sponsors because "it can take a number of years after a project receives FFGA for a Before and After Study to be completed. It can take several additional months for the project sponsor to synthesize and evaluate all the information collected." (LaHood 2009). Since the Before and After Studies guidelines require that there be at least a two-year implementation period after a project is opened and before data are collected, the first FTA Before and After Studies Report to Congress did not occur until 2007.

A summary Report was expected in 2006 and 2009 but, due to the circumstances described above, no project sponsor had completed its two-year implementation period for inclusion in those FTA annual reports. In 2007 and 2008, FTA was able to provide summary reports to Congress on the projects described below. Therefore, the following three Before and After Studies have been summarized in FTA's Annual Report to Congress and represent the universe of all Before and After studies that have been completed to date.

1. Utah Transit Authority: Medical Center Extension (MCE) of the Salt Lake City TRAX light rail system-a 1.53-mile extension of the existing Salt Lake City East-West line running from downtown to the University of Utah, which includes the Medical Center. A Full Funding Grant Agreement for the MCE was signed with FTA in May 2002, and the MCE began operation on September 2003. A draft of the MCE Before \& After Study Report was submitted to FTA in December 2006 and was included in its 2007 Before and After Studies Report to Congress.

2. The Tri-County Metropolitan Transportation District of Portland, Oregon (Tri-Met) - a light rail transit system that is a 5.8-mile Interstate Metropolitan 
Area Express light rail project. A Full Funding Grant Agreement was signed in September 2000 and began operation in September 2004. A draft Before and After Study report was received by FTA from TriMet in November 2007 and included in its 2008 Before and After Studies Report to Congress.

3. Puerto Rico Highway and Transportation Authority's Tren Urban Heavy Rail Project-a 10.7-mile double track heavy rail/ train system in San Juan region. A Full Funding Grant Agreement was signed in July 1999, and the project began full operation in June 2005. FTA received the draft Before and After Study Report from the project sponsor in March 2008 and included this report in its 2008 Before and After Studies Report to Congress.

While providing valuable evaluative information and data on operations of New Starts projects, these three case studies also illustrate some of the procedural and methodological issues that confront project sponsors in implementing an evaluation study mandate.

\section{Capital Cost Findings of Case Studies}

The Before and After Study guidelines request that sponsors provide forecasts of project costs (capital, operating, and maintenance) early in the New Starts planning process. Furthermore, two years after completion of the project, the guidelines require that similar cost data be collected in order to make comparisons of the "after" data with the predictions. Table 1 presents a summary of the forecasted (or "estimated") and actual data that were provided by the sponsors of the three case study projects.

Table 1. Costs and Ridership Data in Three New Starts Transit Projects

\begin{tabular}{|l|c|c|c|c|c|c|c|}
\hline & $\begin{array}{c}\text { Total } \\
\text { Miles } \\
\text { of } \\
\text { Service }\end{array}$ & $\begin{array}{c}\text { Estimated } \\
\text { Captital } \\
\text { Costs } \\
\text { (millions) }\end{array}$ & $\begin{array}{c}\text { Actual } \\
\text { Capital } \\
\text { Cost } \\
\text { (millions) }\end{array}$ & $\begin{array}{c}\text { Estimated } \\
\text { Capital } \\
\text { Cost per } \\
\text { mile } \\
\text { (millions) }\end{array}$ & $\begin{array}{c}\text { Actual } \\
\text { Capital } \\
\text { Cost per } \\
\text { mile } \\
\text { (millions) }\end{array}$ & $\begin{array}{c}\text { Estimated } \\
\text { \# of riders } \\
\text { (per day) }\end{array}$ & $\begin{array}{c}\text { Actual } \\
\text { \# of riders } \\
\text { (per day) }\end{array}$ \\
\hline $\begin{array}{l}\text { Utah } \\
\text { Light Rail }\end{array}$ & 1.53 & $\$ 89$ & $\$ 84$ & $\$ 58.4$ & $\$ 54.6$ & 4,100 & 2,640 \\
\hline $\begin{array}{l}\text { Portland, OR } \\
\text { Light Rail }\end{array}$ & 5.8 & $\$ 283$ & $\$ 350$ & $\$ 48.8$ & $\$ 60.3$ & 13,900 & 11,800 \\
\hline $\begin{array}{l}\text { Puerto Rico } \\
\text { Heavy Rail }\end{array}$ & 10.7 & $\$ 1,250$ & $\$ 2,250$ & $\$ 116.8$ & $\$ 210.3$ & 114,500 & 24,700 \\
\hline
\end{tabular}

Source: Compiled by author from Federal Transit Administration, Before and After Studies of New Starts Projects: A Report to Congress. 2007 and 2008, Washington, D.C.: U.S. Department of Transportation. 
These data supplement the ongoing performance data (called Section 15 data) reporting that is required of all transit providers, with the key difference being that Section 15 data is a uniform annual accounting of costs and service (e.g., cost per mile, cost per passenger, ridership) of the overall transit system, while Before and After Studies provide project-specific longitudinal comparative data (Black 1995).

The New Starts transit projects, as summarized in Table 1, reveal that clearly there is great variation among the projects with regards to their forecasted and actual capital costs. One very important issue that is highlighted in Table 1 is the major capital cost overruns that occurred. For example, the reasons given for the before and after cost discrepancy in the Portland Light Rail project included:

- Change in reporting instructions between the two timelines, requiring $\$ 11.3$ million more for start-up and interim financing in final cost.

- Increased number of vehicles purchased.

- Increased costs for communications and signals.

- Increased costs for rebuilding rather than modifying a bridge.

- Increased costs for rights-of-way associated with the number of easements required for implementation. (Federal Transit Administration. 2008).

Puerto Rico's heavy rail project experienced the greatest before and after capital cost discrepancies when compared with the other two case studies, with an 80 percent overrun. The 2008 FTA report claims that this discrepancy is attributed to several factors such as the lack of quality "before" data and operational problems such as:

- The contractor bids were higher than the original estimates.

- As design progressed, the following changes were made in several of the project characteristics: exercise contract options for two additional stations, exercise contract options for adding 10 vehicles, unforeseen site conditions, and refinements to the scope of the project.

- Project delays due to lack of qualified construction personnel, weather conditions (three hurricanes), interface coordination issues, design changes while construction was under way.

- The extended schedule and delays required additional support for the Project Management and Construction Management services consultants as well as additional in-house administrative support. 
- Increased right-of-way costs.

- Settlement agreements-all contactors requested additional time and money due to weather, complexity of the project, numerous interface coordination issues, and evolving design control while construction was under way.

- Acceleration payments for contract completion were given to several contractors. (Federal Transit Administration. 2008).

Finally, the before and after capital costs experienced by the Utah Light Rail Transit project demonstrated best practices among the three projects, with the actual capital costs being less than the projected costs. The Utah Transit Authority suggested that the reduction in costs was due to "efficiencies gained by allowing the construction contractor that had just completed the University Light Rail Transit line to immediately initiate construction on this line" (Federal Transit Administration 2007).

\section{Ridership Findings of Case Studies}

As was discovered with capital costs, ridership also reflected significant differences when comparing Before and After project data. Table 1 illustrates that in all three case studies, the actual ridership outcomes were much less than projected amounts. For example, Portland's Light Rail Transit ridership data for 2008 was 15 percent less than expected. The reason for the discrepancy was attributed to the forecast model, which was affected by the following operational problems:

- The actual number of jobs in the corridor was 27 percent less than predicted.

- The travel model output shows that 53 percent of all rail riders were commuters, whereas the results of a transit on-board survey indicated only 40 percent were commuters.

- The park-and-ride modeling assumptions were overly optimistic.

- Predicted rail speeds were 8 percent higher than actual.

- Some transfer and walk connection assumptions were overly optimistic. (Federal Transit Administration 2008)

Due to the fact that Puerto Rico's project involved construction of a new high capacity, metro subway system, their forecasts for ridership were very high but, ultimately, the project achieved only 23 percent of anticipated riders per day in 
the first two years of operation. Some of the reasons for the lower than expected ridership were:

- Observed ridership was 24,700 average weekday rail passengers in Year 1 (2005-2006) and 26,900 in Year 2 (2006-2007).

- Predictions were 114,500 weekday rail passengers in 2010.

- Predictions were based on a project change from 14 to16 stations plus changes to the surrounding bus network to result in 113,100 weekday rail passengers in 2010.

Furthermore, the forecasting modeling errors in the Puerto Rico project appear to be due to a combination of the following factors:

- The travel model specifications may have been too favorable for use of rail over auto and bus choices.

- The assumed flat fare for riding the rail was significantly less than the actual implemented fare.

- The coded transit network did not adequately represent the private and public bus services that offered the public a competitive alternative to use of rail.

- The predicted travel times were lower than actual.

- The model overestimated the amount of intermodal integration that actually occurred at the rail stations (e.g. the model predicated more than $50 \%$ of all rail riders will arrive at a station by a bus rather than walking or driving, but survey data shows the actual number is less than $20 \%$ ).

- In spite of the model's over-prediction of total rail riders, it under-predicted the number of park-and-ride and kiss-and-ride users, which may have influenced the construction of an insufficient number of parking spaces to satisfy actual park-and-ride demand.

- Population was assumed to grow by 19 percent from 1990-2010, but Census data for the 1990 to 2010 periods shows a growth of only 5.4 percent. (Federal Transit Administration 2008)

Before and After ridership data for the Utah Transit Authority were provided in the 2007 FTA report to Congress and, similar to the capital costs findings, the Utah Light Rail Transit system forecasted ridership that was not realized in project implementation. The reason for this outcome was attributed to problems with 
the forecast model, which was implemented by the metropolitan planning organization (called WFRC) and not the Utah Transit Authority.

The Utah project sponsor described these forecasting problems as follows:

Over the course of project planning from 1993 to 2001, the WFRC updated its travel models and in the absence of a requirement for Before and After Studies, retained only sparse documentation of the forecasts. The many details of the forecasting process and of the key drivers of forecasts were not archieved and were no longer available when the requirement for a Before and After Study was established. Further because the Medical Center Extension project was not treated as a separate project during the planning stages, forecasts of ridership are an undifferentiated component of the forecasts for the entire University LRT Line (Federal Transit Administration 2007).

The discrepancies identified above between forecasted and actual cost and ridership data is not a surprise to transit planners familiar with the problems associated with transportation forecasting. Through the years, several analysts have criticized the inaccuracies and potential for bias associated with large scale transit project forecasting. As a result, "new generation rail systems have failed to produce the ridership that was promised and ended up costing far more than was forecast" (Pickrell 1989; Cervero 1998).

\section{Lessons Learned from Case Examples}

We have shed light on the links between the pragmatic forms of knowledge/ concepts used in action and the academic and formal knowledge/concepts disseminated in the literature. The two are not disconnected so the detour via evaluators' practices and pragmatic conceptualization opens wide perspectives for research and theorization in evaluation (Tourman 2009, 28).

Analyzing the Before and After Studies of transit projects reveals some lessons regarding the practice of evaluation that can help make transit-related mandated evaluation research more effective. The objective of this paper was to describe the characteristics of the Before and After Studies mandate, the findings of the Before and After Studies that have been implemented to date, and analyze the implications of these Before and After Studies in federal the transit field. Therefore, the outcomes of the utilization of pragmatic and academic forms of knowledge as 
demonstrated in FTA's Before and After Studies have led to the following lessons learned:

\section{Lesson Learned \#1: FTA's Before and After Studies mandate strengthens the validity of FTA's evaluation data by employing a Quasi-Experimental evaluation research design.}

Before and After Studies represent an effort on the part of FTA to increase the sophistication of evaluation research design by moving from a Non-Experimental collection of one-time "after-only" data (e.g., Section 15 performance data) to Quasi-Experimental "pre-test and post-test"design. Of course, this approach is not a controlled Experimental design, because the design is lacking random assignment of a sample population and the use of experimental and control groups. Instead, Quasi-Experimental evaluation represents a feasible research design that provides more credible data on the important role that transit can play in improving mobility and quality of life in communities throughout the country (Federal Transit Administration 2008).

\section{Lesson Learned \#2: The Before and After Studies experienced difficulties in accurately forecasting costs and ridership, which must be addressed in FTA's data collection and forecasting guidelines.}

Previously in this paper, the issue of producing reliable forecasts was discussed as a common problem facing transportation planners. Exacerbating this problem is the fact that the three case studies described included projects that were initiated before FTA had developed clear data collection and forecasting guidelines. Therefore, most projects reported some discrepancies between before and after data and among different transit projects. Specifically:

- The forecasting model that Portland used in the Before and After Study overestimated the percentage of riders who were commuters.

- Portland's park-and-ride and walk-and-ride assumptions were too optimistic.

- Puerto Rico discovered that its travel model favored use of rail over other modes and so ridership in park and ride and bus was underestimated.

In response to the need to collect quality, consistent data, FTA issued guidelines in 2006. Since Utah's study was implemented after the adoption of these data collection guidelines, Utah's relative success in producing more accurate forecast data indicates that these new data collection procedures were helpful in addressing this problem. 


\section{Lesson Learned \#3: Closer intergovernmental cooperation is needed in imple- menting mandated evaluations of public programs.}

In general, most metropolitan areas in the United States have divided implementation of transit management and planning among separate agencies. Management is usually the responsibility of the regional transit authority, while planning is conducted by the metropolitan planning organization (MPO). This division of responsibility among two different agencies created problems in implementing the Before and After Studies mandate because it required cooperation and coordination among these different agencies. Several of the case study cities identified problems in achieving cooperation such as:

- Utah's MPO did not fulfill its role of collecting and archiving forecasted data.

- Puerto Rico reported that costly delays were caused by problems in coordinating consultants with in-house staff.

In conclusion, the Before and After Studies requirement can provide an important new direction for evaluation of large-scale transit projects if the federal mandate provides clear guidance as to Quasi-Experimental research design, data collection, forecasting procedures and addresses process issues such as intergovernmental coordination. By comparison, the effectiveness of FTA's Section 15 performance reporting procedures have proved to be limited in addressing these issues.

\section{References}

Bernick, M., and R. Cervero. 1997. Transit Villages in the 21st Century. New York: McGraw Hill.

Black, A. 1995. Urban Mass Transportation Planning. New York; McGraw Hill.

Carman, J., and K. Fredericks. 2008. Government and accountability: Paving the way for nonprofits and evaluation. New Directions for Evaluation 119: 5-12.

Cervero, R. 1998. Transit Metropolis. Washington, D.C.: Island Press.

Cervero, R., et al. 2004. Transit-Oriented Development in the United States. Washington, D.C.: Transportation Research Board. TCRP Report \#102.

Dittmar, H., and G. Ohland. 2004. The New Transit Town. Washington, D.C.: Island Press. 
Federal Transit Administration. 2003. Before and After Study Qs and As. Washington, D.C.: U.S. Department of Transportation: 1-3. Full text available at www. http://www.fta.dot.gov/planning/newstarts/planning_environment_2613. html.

Federal Transit Administration. 2008. Before and After Studies of New Starts Projects: Report to Congress. Washington, D.C.: U.S. Department of Transportation: 3-8. Full text available at http://www.fta.dot.gov.

Federal Transit Administration. 2007. Before and After Studies of New Starts Projects: Report to Congress. Washington, D.C.: U.S. Department of Transportation. Full text available at http://www.fta.dot.gov.

Fisher, R., and S. Libberton. 2003. Before and After Studies for New Starts Projects. Washington, D.C.: Transportation Research Conference.

Frankfort-Nachmias, C., and D. Nachmias. 1996. Research Methods in the Social Sciences. 5th ed. New York: St. Martin's Press

La Hood, R. 2009. Letter from the Secretary of Transportation, U.S. Department of Transportation to Congress, December 14.

Manksi, C. 1990. Where we are in the evaluation of federal social welfare programs. Focus 12(4): 1-5.

Pickrell, D. 1989. Urban Rail Transit Projects: Forecasts vs. Actual Ridership and Costs. Cambridge, MA: Volpe Transportation Systems Center.

Tourmen, C. 2009. Evaluator's decision making: The relationship between theory practice, and experience. American Journal of Evaluation 30: 7-30.

\section{About the Author}

David LAVerny-RAFTeR, Ph.D., AICP (rafter@mnsu.edu) is a Professor of urban planning, transportation and policy analysis at Minnesota State University-Mankato and served on the Adjunct faculty of the Humphrey Institute of Public Affairs at the University of Minnesota. He has held Fulbright Visiting Professor positions at Trinity College Dublin and University College Cork (Ireland) and worked as an evaluator of transportation programs and policies with the U.S. Government Accountability Office and the Minnesota Office of the Legislative Auditor. His research interests include transit as a key element in sustainable transportation planning. 